This qualitative study invited women living with cancer who engaged in visual art-making to reflect on their experiences of the creative process. The study sought to explore whether the participants described experiences of flow during art-making and, if so, how such experiences helped them to cope with cancer. Ten women took part in semi-structured interviews. They described a range of difficulties associated with their illness. The interview data were analysed using a template approach, based on the theory of Csikszentmihalyi.

The participants described a number of experiences that have been associated with flow in previous work. However, one aspect of flow, namely having clear goals, was not present clearly in the participants' accounts. The participants also described other facets of art-making that seemed part of the flow experience, including sensuous vitality, responsiveness to art materials and evolving imagery, and creative adventures. The flow experiences during art-making helped to banish intrusive thoughts about cancer, provided valued experiences of mastery and control and encouraged the participants to engage in positive journeys into the unknown, thereby alleviating some of the stress of cancer.

The study offers a detailed analysis of the experience of creative occupation and has relevance to occupational therapists working with clients who have life-threatening illnesses.

\title{
Creative Adventures and Flow in Art-Making: a Qualitative Study of Women Living with Cancer
}

\author{
Frances Reynolds and Sarah Prior
}

\section{Introduction}

A diagnosis of cancer is recognised as highly fear-arousing. People not only face the discomforts of potentially disfiguring medical treatment but also confront issues of mortality. Even those who have completed treatment tend to 'live with' cancer for many years, because they remain subject to intrusive thoughts about cancer and concerned about possible recurrence and metastasis (Saegrov and Halding 2003, Laubmeier and Zakowski 2004). As well as creating worry and vigilance, cancer imposes what has been described as a biographical disruption (Bury 1982). After such a diagnosis, the person may feel that valued life goals are unattainable. The assumptions that guided life before cancer may be shattered and the person may feel disconnected from the familiar self, observing - from the avoidance or the pity of others - that only a stigmatised cancer identity remains (Frank 1991, Mathieson and Stam 1995). Facing such a combination of physical, emotional, cognitive and social stressors, it would seem difficult for people with cancer to construct a life of positive quality. Yet research studies suggest that many people devise resourceful coping strategies.
Some people cope by reprioritising their goals to enjoy more authentic relationships and activities. Some even come to re-evaluate their illness as having catalysed certain positive changes (for example, Mathieson and Stam 1995, Carpenter et al 1999, Urcuyo et al 2005). However, previous research has tended to neglect the potential contribution of meaningful occupations to maintaining or regaining subjective wellbeing in cancer.

Flow has been conceptualised as a particular type of optimal experience associated with 'vital engagement', a deep involvement in activities that are significant to the self and that promote feelings of aliveness or vitality (Nakamura and Csikszentmihalyi 2002, p83). To what extent vital engagement offers people living with cancer a source of subjective wellbeing has received little previous examination in the occupational therapy literature. This issue is addressed here.

\section{Literature review}

The experience of flow has been explored extensively by Csikzsentmihalyi (for example, Csikszentmihalyi 1990, 1996, 1997) and considered relevant to occupational 
therapy (Emerson 1998). Flow refers to a psychological state characterised by intense concentration and full involvement in an activity. Flow provides 'flashes of intense living' (Csikszentmihalyi 1997, p29). There is a focus on the 'extended present' and perceptions of time alter, seemingly passing more slowly or more quickly during the flow state (Nakamura and Csikszentmihalyi 2002, p90). Such concentrated attention is helpful in banishing negative thoughts about, for example, the self.

People approach tasks that promote flow with a sense of confidence and control, rather than fearing failure. There is an enjoyable process of discovery as the task unfolds. Flow activities stimulate the development of further skills, thereby avoiding boredom and stagnation. There is a need for a 'just right' challenge, however, because excessive task difficulty creates anxiety rather than optimising flow (Rebeiro and Polgar 1999, p14). Flow states have been studied in a range of leisure occupations, from sports to sedentary activities such as keeping scrapbooks, cake decorating, listening to music, viewing works of art and creative writing (Csikszentmihalyi 1990, 1996, Dickerson 2000, Scheerer et al 2004).

Csikszentmihalyi (1990) argued that flow depended upon having clear goals and clear feedback. These enabled the people carrying out the task to determine their standards of performance and decide what they needed to do next. He noted that the occupational context and the intrinsic interest in the activity helped people both to withdraw attention from everyday preoccupations and anxieties and to block out environmental distractions.

Why is flow associated with optimal psychological wellbeing? In addition to encouraging the development of skills, flow promotes strong feelings of accomplishment, control and autonomy. During flow, the person lives more vividly in the present moment. It is also a state in which the person feels coherent and at one with the environment, rather than fragmented by numerous thoughts, ambivalent motivations and distractions. Csikszentmihalyi (1990) argued that self or personal identity emerged more strongly after going into temporary abeyance during flow activity.

Very little research has been carried out on the flow experiences of people living with cancer. Arguably, flow experiences have a distinctive contribution to make to people's subjective wellbeing after such a diagnosis. Flow may enhance subjective wellbeing by temporarily banishing intrusive thoughts about illness and mortality and by refocusing attention away from pain and other symptoms. The autonomy and accomplishment inherent in flow experiences might help to challenge the profound feelings of helplessness that cancer so often induces. Flow experiences may strengthen self-confidence, helping to counteract the debilitating effects of cancer on personal and social identity.

These arguments were supported by Tocher (2002), who interviewed 22 women who had joined with other breast cancer survivors to form dragon boat racing teams. They described their sport as having a wide range of therapeutic benefits, including camaraderie with other cancer survivors, self-esteem, optimism and physical resilience through training and competition. Their accounts included flow-like experiences. For example, some reported a loss of their usual sense of self whilst engaged in racing. 'When I enter that boat I take on a persona that doesn't appear in my everyday life. I become somewhat ruthless and aggressive to win the race' (p105). The participants often made some reference to the experience of meeting the exacting demands of the sport with a level of skill that sometimes surprised them: 'I push myself to the limit ... it really gives me a sense of control over my life' (p106). The participants reported being thoroughly focused on the present moment during racing, concentrating on putting 'every ounce of weight behind each pull' (p107). While they were so focused on the task of racing, the women's cancer-related concerns subsided, offering some relief from the intrusive presence of illness. Racing also provided positive exhilaration, counteracting the daily drag of treatment and worry.

Other studies of meaningful occupation among cancer survivors also highlight flow as one therapeutic aspect of the experience. Like Tocher (2002), Unruh and Elvin (2004) interviewed women who had had breast cancer and had taken up dragon boat racing. The participants described deriving many benefits from their sport, including social support and physical wellbeing, confidence and control. They also described flow-like states. For example, one participant reported feeling 'the oneness in the boat', which suggested a loss of self-awareness during racing (p143). Their desire to do their best suggested a strong focus on challenge and the emergence after racing of a positive self-image also agreed with Csikszentmihalyi's analysis of flow.

Unruh et al (2000) explored the meanings of gardening for breast cancer survivors. Again, some of the subjective benefits of this occupation related to flow. The authors argued that this occupation was restorative because it bought the person fully into the present moment and consumed attention. It therefore helped to provide temporary relief from thoughts about cancer.

\section{Purpose of the study}

This qualitative study sought to understand whether women living with cancer who engaged in visual art-making described experiences associated with the flow state and, if so, whether flow experiences helped the participants to live more positively with cancer. For this study, visual art-making embraced any art or craft activity, such as textile art, pottery, painting and collage. The analysis presented here focused specifically on the aspects of the experience that could be interpreted as flow. Other therapeutic or restorative aspects of art-making, such as enjoying social contact and gift-making, were evident in the accounts but are not explored further within this paper. 


\section{Method}

\section{Methodology}

Qualitative research embraces many different traditions, although there are a number of commonalities (Miles and Huberman 1994, Marshall and Rossman 1995). This research aimed to gather rich insider descriptions of the creative process. The data analysis was guided by a template approach (Miles and Huberman 1994, Reynolds 2003). The template approach, using a start-list of themes devised a priori, enables a qualitative researcher to test the relevance of previous theory and/or research findings to current qualitative data.

This approach was appropriate for the present research because its purpose was to examine the extent to which the participants referred to flow experiences in their accounts, as defined by Csikzsentmihalyi. Since flow is not a widely understood concept outside psychology and occupational therapy, the participants were not expected to use this term explicitly to describe any of their experiences of art-making. Instead, the researchers applied the defining features of flow as a coding frame to determine the extent to which the participants made reference to these features in their accounts of art-making.

\section{Participants}

Following ethical approval from Brunel University, participants were recruited through advertisements for volunteers posted in United Kingdom national arts magazines. All were given full information, including main interview questions, prior to giving consent for the interview.

Ten women who reported a diagnosis of cancer were recruited. Their ages ranged from 23 to 66 years, with most aged between 47 and 57 years. The participants had received various cancer diagnoses. This variation of diagnosis within the sample was considered an advantage when exploring commonalities in the meanings of art-making for people coping with this disease. They lived in many areas of England. All were white. Eight disclosed that they were married or living with partners and most of these had adult children. Most had previously been employed in professional or white-collar occupations and all of these had discontinued regular paid work since becoming ill.

All participants had lived with cancer for at least one year, which provided some emotional distance from the initial stress of diagnosis and early treatments. Five continued to have active treatment for their conditions and five regarded themselves as survivors. Such mixed samples have been included in previous studies of the lived experience of cancer, because both survivors and those in current treatment often report concerns with cancer recurrence, metastasis and long-term side effects of treatment (for example, Unruh et al 2000). The survivors in this study also reported such concerns.

\section{Design and procedure}

Qualitative interviews were selected as the method of choice because they could provide richly detailed personal accounts of the experience of art-making. Semi-structured interviews were chosen because they have the advantage of being both able to explore commonalities in participants' experiences and flexible enough to probe unexpected responses.

The interviews lasted 60-90 minutes. Seven interviews were carried out in participants' homes and three were conducted by telephone according to participants' preferences. All were audiotaped and fully transcribed. The interviews explored the participants' experiences of cancer, reasons for taking up art-making and experiences during art-making, as well as the ways in which art-making contributed to their subjective wellbeing when living with cancer.

\section{Data analysis}

The experiential themes or codes being looked for in the interview data were theorised features of flow: challenge; intense concentration; reduced awareness of environment and self during activity; sense of altered time/extended present; development of skills; feelings of confidence/achievement during and after the activity; clear goals; and feedback. The researchers cross-checked their thematic codings to enhance the confirmability (reliability) of the findings (Marshall and Rossman 1995). Of course, when researchers apply a ready-made conceptual framework to qualitative data, it is important to look also for disconfirming evidence. Hence, the present researchers remained sensitive to any further themes within participants' accounts that seemed intrinsic to the flow state yet were relatively neglected in previous theorising. In all quotations that are presented, pseudonyms are given.

\section{Findings}

First, a brief résumé of the participants' experiences of cancer is given. These accounts show that the sample was not unusually stoic or defensive, because the participants described many of the stresses reported in previous research. For example, the participants described the early stages as marked by shock, harrowing treatments, chilling preoccupations with death and difficult decisions about whether or not to give up work. Some recounted their sadness at losing certain social relationships, when friends who were uncomfortable with cancer withdrew from their social circle. Many participants referred to a loss of self-confidence or self-worth in the early stages of cancer and their need for occupations that would fill empty time. Some participants described struggling to accept their cancer. Yet acceptance allowed the release of creativity and a positive recommitment to life. Jessica, with breast cancer, recounted:

I've written everything down, even down to planning my own funeral ... because I think once you've done that and you've put it somewhere, then you forget about it because it's already dealt with. I think that the creative side is what you do from day to day. 
In this sample, art-making was mostly discovered or intensified after diagnosis rather than being a lifelong interest. It appeared to serve many purposes in the participants' lives, including restoring self-worth, presenting non-cancer topics to talk about with friends and providing the satisfaction of raising money for charity. Art-making was a means both of normalising everyday life and for coping with the problems of cancer. These wider benefits will be explored in other papers.

In describing the creative process, the participants accounts were replete with references to flow-like states. The main features of flow, as described by Csikszentmihalyi, are presented and are illustrated by quotations from the interviews. Then certain further experiences are considered which also seemed to promote flow.

\section{Challenge}

Csikszentmihalyi (1990, 1996, 1997) argued that tasks needed to present a certain level of challenge to elicit flow. Nearly all the participants enjoyed art-making because the challenges that it presented in their daily lives were distinct from those presented by their cancer. Artistic challenges were welcomed not only because they brought stimulation and interest into daily life but also because unlike cancer - they could be mastered through personal effort. Helen had had several health complications following her treatment for non-Hodgkin's lymphoma, including a degenerative hip condition. She described taking up an advanced embroidery course as a response to her worsening health:

I started limping with my hip going wrong and ... so I thought 'Well, this will give me the mental challenge'. I can't do so much [physically] so I'm going to learn how to design.

In conveying the process of her experimental textile art, Helen recounted many of its challenges. For example:

I've started actually stitching and sewing into wire mesh ... It's awkward but you can still achieve it and then you have the rigidity or the twisting that makes it do other things ... the sky's the limit, you just don't stop thinking.

Marie's blood condition was life-threatening and yet she described choosing textile art media which took her outside her comfort zone:

I chose the felt because I like to challenge myself and say,

look, I don't like felt, how am I going to make it so that I do like it? I mean I love silk paper, I just love it and I could do all my work in silk paper. But it's not so much of a challenge ... [you need to] find how to make it ... meaningful to you.

Several participants cautioned that they needed a 'just right' challenge in the context of their illness, the demands of treatment and other life stresses. The art-making that they engaged in should be neither too easy or repetitive nor too stressful. Jessica, for example, thought it important to set herself an appropriate level of challenge, reflecting her current mood and state of health:
If I'm not feeling very confident, I do cross-stitch. Whereas if I'm in a more confident mood, I'll paint.

These views seem to reflect an awareness that the challenge of an activity needs to be set at a level that matches current skills and attention, because these fluctuate according to the demands of the illness, the stress of the treatment and other factors. Only then can the task offer an opportunity for mastery and achievement and help to counteract the powerlessness induced by cancer.

\section{Intense concentration}

All participants referred to the intense concentration that their art-making demanded. They described being 'absorbed' or 'engrossed' in their artwork. This helped them to learn new skills and also helped to banish intrusive thoughts and fears about cancer for that period of time. Attention could not be focused equally on the task in hand and the illness. Susie, with metastatic breast cancer, illustrated this experience in relation to cross-stitch:

It takes enough concentration for me not to be thinking about anything else and just to be thinking about the stitching, because then I'm not thinking, 'Oh, when am I going to be better?', you know, and 'Why did this happen to me?' It takes my mind off everything and it's not too tiring.

Patricia had found her textile art helpful for coping with cancer:

It's focusing the mind by having something to concentrate on that stills your mind ... and it's not dwelling on all your problems and letting them get out of proportion.

For the task to be consuming of attention, it had to have the 'just right' challenge, as noted above: a balance that varied from person to person, depending on personal needs and current state of health. Some perceived their most creative work to be situated on a cusp between stimulation and frustration. Sometimes the participant found that her skills were adequate for the challenge of the task and sometimes they were not. Marie stated:

I started off doing a lot of work with silks and ready-made cloth but then I found that it wasn't quite right. From then on, I've been making my own fabric and really enjoying that, when it doesn't get me frustrated.

Learning to manage this frustration was important for enabling flow.

Intense concentration was sometimes called for between episodes of art-making. Thoughts and plans about artwork increased vitality and also refocused thoughts away from cancer. As Marie explained:

There's just so much work in them [the textile art pieces] and so much creative thinking time. Sometimes you're not actually sitting at a sewing machine ... you're cogitating about how to achieve the next effects.

\section{Sense of altered time/extended present}

When engrossed in art-making, the participants enjoyed a 
different relationship with time. Helen commented: 'You think "that was two or three hours gone".' The period of time that was spent focused fully on the creative artwork was time away from worry or preoccupation with pain. For example, Jessica had found that her altered awareness of time, and deep concentration, during artwork helped in pain management:

Once you've started, before you know it, half an hour's gone by and for example, if the pain is really bad and you take something and it doesn't work, if you can get into some black work [embroidery using a single colour thread], in about half an hour, you feel better, rather than just sitting there and going, oh my God, it hurts, it hurts, it hurts. Oh yes, that's definitely useful.

\section{Reduced awareness of environment and self}

Linked to the subjective experience of altered time and full concentration, the participants reported being less aware of their health, pain, stress or surroundings during the creative task itself. However, through their commitment to art-making, many participants described becoming more observant and appreciative of their surroundings in daily life at other times. They often used these sharpened observations in their creative designs. According to Helen:

I can just walk up the Downs and just look at the view ... You just sort of sit there and think you're just so lucky to be here.

\section{Developing skills}

Almost all the participants emphasised their commitment to learning more about their preferred forms of artwork and developing further skills. Many had started out with very basic art or craftwork skills and referred to their first attempts as disappointing. Carol reflected on her patchwork quilt making:

That [first] quilt was quite a hotchpotch ... it's not expert, I can see lots of things wrong with it, but probably other people wouldn't. You know my corners aren't really nice and square ... But then I went on and did a second one which was a pukka [good quality] one.

The theme of persevering to achieve an artistic vision was common in the interviews. Patricia described her efforts to represent rocks, stones and lichens artistically:

I'm interested in the shapes and forms of rocks and stones ... Certain particular shapes recur that I can't get right and I'll try various versions and persevere ... and do various versions again and again.

Several participants emphasised the value of gaining advanced skills in order to achieve greater success with freestyle or personal designs. According to Helen:

Whatever you do, you have to learn how to do it traditionally and then ... you can do it experimentally.
The development of skills seemed to help the participants to maintain a positive identity, even in the face of deteriorating health.

\section{Feelings of confidence/achievement during and after the activity}

Several participants described how their self-confidence plummeted after the cancer diagnosis, using expressions such as feeling 'battered', 'worthless' and 'defeated'. For Csikszentmihalyi, flow states promote feelings of achievement and thereby strengthen self-worth. These outcomes were abundantly clear in the participants' accounts of their art-making. As a result, the participants seemed to gain powerful subjective resources for dealing with the negative effects of cancer on self-image.

Tangible products helped to show others that the participant was not to be defined by the cancer label. Louise explained:

You're still part of everyday life, aren't you, you know, you're just not sitting there being ill all the time, [when engaged in art] you're actually achieving something.

For some, life with cancer had changed in positive as well as negative ways. Marie, a retired lecturer, explained:

I see that the disorder has given me the opportunity to do what I want and it stops me doing what I want sometimes ... I get a sense of achievement like I used to get a sense of achievement out of getting research contracts, my PhD students through their vivas or whatever. Now I get a sense of achievement which is equally as strong from having a piece in an exhibition or feeling good enough about what I do to hang it on my wall.

Feelings of achievement were also derived from the autonomy and control inherent in art-making. This remained an area of life which 'you can do something about' (Marie). Art provided an antidote to the relative powerlessness that many felt about their cancer. Jean explained that her illness had taken away some of her social roles, but that at least she retained autonomy over her art:

You take responsibility for it, you can't give it to somebody else ... This is your own, it doesn't move anywhere unless you move it.

\section{Clear goals and feedback}

There was some agreement that art provided immediate feedback. Some participants emphasised the satisfaction of seeing their work 'building up' (for example, Susie). Several compared their artwork with that of others; for example, Marie stated:

I walked around the [exhibition] room and looked at everybody else's and I thought 'Well, mine's OK then'.

Some enjoyed external feedback, for example from family or from visitors at exhibitions.

Did participants have clear goals in relation to their artwork? This was more difficult to decide. Certain interim deadlines (such as those set by art tutors) were valued 
for encouraging commitment to art-making. They provided alternative milestones to progress that were distinct from cancer treatment appointments. Rather than professing the need for clear goals there was a stronger narrative within the interviews, namely that art-making afforded intriguing journeys into the unknown. Even among those who had fairly clear goals at the outset of an art project, the journey to get there remained shrouded in mystery. This theme is explored in further detail below.

\section{Further features of the art-making experience}

The participants referred to additional aspects of the art-making experience that seemed to be part of the flow state. Such experiences have received less attention in the flow literature to date and are described next.

\section{Sensuous vitality}

Many participants recounted feeling very alive when engaged in art-making. Part of this feeling seemed to be associated with the highly sensual and aesthetic aspects of the experience. For example, Carol reported being drawn to create many pictures of leaves because she loved the colours so much ... they're so vibrant, they look fantastic'. Eve celebrated the feel of a 'squidgy brush' when painting. Smells of fabrics, paints and chemicals were intimately bound up with the art-making experience. Helen explained a textile art technique that involved stitching on acetate fabric:

... and then you get some acetone and you go outside because it's very fumy, and you immerse the fabric in the acetone and the acetate disappears [dissolves] and all you're left with is the thread ... it's like cobwebs in Autumn.

Although the sensual aspect of the art-making could be understood to promote immersion in and concentration on the activity, it also seemed to foster the experience of oneness with the task, and a temporary loss of self during the creative process, all of which are considered aspects of flow.

\section{Flexible responsiveness}

The participants described a strategy of flexible responsiveness as essential to their art-making. 'I go with what grabs me,' explained Jill. The participants emphasised that the most satisfying artwork tended to emerge not from tight planning or from having clear goals, but from a certain intuitive adaptability to the art medium or evolving image.

Carol described making patchwork cushions with fish motifs inspired by a design in some of the fabric:

I thought that the fabric looked just like fish scales, so I cut them out as a fish shape and then I embroidered round those shapes and I thought yes it does look like fish scales. And I was so pleased with that.

Later on, Carol was even more explicit about the need to be adaptable and responsive to emerging images. When painting skies, she explained:
I can't actually get the sky I think I'm going to get. I have to work with the sky that sort of appears out of the paper.

Such organic or evolutionary growth in textile art was also described in some detail by Patricia:

What happens is that I have a vague-ish idea in mind. I will assemble a lot of stuff that might be useful to realise the sort of half-ideas that I have ... I'd have a colour theme in mind and I'd start with that and then it would grow in a more organic kind of way, according to what I thought the design needed as it developed rather than having it all laid out first.

Although flexible responsiveness might seem attractive to anyone engaging in creative pursuits, it had especially therapeutic meanings for the participants who were living with the uncertainties of cancer. As well as helping them to immerse themselves in their creative work and to banish thoughts about illness, a responsive mode of being helped to counteract the experiences of subjugation and constraint imposed by their illness and its treatment. Jean was very clear about this. Having described an enjoyable exploratory session of needlework, she commented:

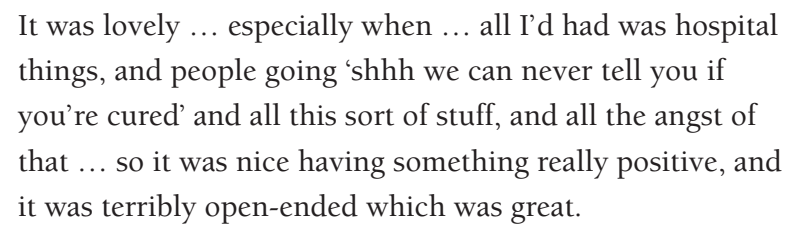

\section{The creative adventure}

As well as emphasising the need to stay responsive when engaging in art-making, the participants represented their experiences in terms best described as a creative adventure. Although not previously identified as a defining feature of flow, adventurous activities could be understood as promoting concentration, exhilaration, oneness with the task and many other flow-like experiences. Some participants described their art-making as a journey, with its own momentum. They could not predict exactly what would happen on this journey, nor could they fail. This suggests that their art-making provided a powerful antidote to the experience of illness, where the failure of treatment was of great concern and where the unexpected would usually be unwelcome rather than a source of excitement and achievement.

Helen enjoyed freestyle embroidery, 'something where you can't go wrong'. Patricia enjoyed marbling fabric for a similar reason:

You can't control it ... It doesn't matter what you get you can make something out of almost anything you've created ...

Even if it's absolutely horrible, you can redeem it simply by tossing it in a dye bath and dyeing over the top ... it's a technique where you never have full control.

The spirit of adventure helped the participants to approach their art-making without fear of failure. As Eve said of her watercolour painting:

It doesn't really matter if sea becomes sky or the landscape becomes seascape. 
Such mistakes could be recovered from and might in any case delight the eye. The subjective sense of exploration and adventure within art-making was clearly described by Marie:

It [art] has absolutely no purpose, it's great. It's incredibly challenging ... when you get an idea for a new project, it's not knowing how to do it at all ... how to get there is just a complete unknown ... it's a real spirit, a voyage of discovery, really. So you've kind of got your goal in mind, but not a really clear idea of the path it's going to take.

Experiential features of flow, such as challenge and developing skills and mastery, are apparent in this extract, yet so too is the notion of creative adventure, that art-making is exciting because it involves a voyage of discovery.

\section{Discussion}

Many aspects of the creative process could be characterised as flow-like, showing the potential complexity of this concept. The participants clearly enjoyed the challenge of creative artwork, responded to their activities with immersion and deep concentration, experienced an altered sense of time and felt more confident through engaging in such occupations. Art-making provided feedback and a positive sense of achievement. Flow-like experiences had a particular therapeutic value for the participants living with cancer in helping to block out worries about illness for the duration of the activity, building a positive self-image that resisted definition by cancer and enhancing subjective control and mastery. Flow-like experiences heightened satisfaction with daily life and offered the participants opportunities for 'vital engagement' (Nakamura and Csikszentmihalyi 2002, p83). Although the participants described being oblivious to time and outside influences when deeply engaged in art-making, many argued that they needed an environment that facilitated creative work. The facilitating effect of context on flow deserves further inquiry.

Csikszentmihalyi $(1996,1997)$ associated flow with clear goals. These help the person readily to judge what actions are required next. However, the participants' accounts did not support this analysis clearly. Instead, their accounts suggested that flow during art-making was associated with maintaining a sensitive responsiveness to the many possibilities within the art materials and evolving images, rather than trying to enact rigid plans. Flow seemed associated with embarking on art-making as a creative adventure, allowing unexpected discoveries to occur along the way. Such experiences can be interpreted as powerful antidotes to the helplessness and psychological confinement that are common for people living with cancer. The participants also made several references to their experiences of sensuous vitality, gained from physical and psychological interactions with the colours, textures and processes of art-making. These experiences also helped the participants to enjoy the present moment and to ward off intrusive concerns with illness. Whether these experiences challenge the traditional concept of flow or expand upon it is open to debate.
The analysis extends previous work (for example, Unruh et al 2000, Unruh and Elvin 2004), showing that people with cancer value flow-like experiences both for enhancing the quality of their everyday life and, more specifically, for refocusing their attention away from concerns with illness, loss and mortality. Nevertheless, the study has limitations. The sample was small, although of an acceptable size for a qualitative study. All participants were white, female and well educated. They were committed to art-making, were highly articulate about their experiences and presumably volunteered for the study in order to share these experiences with others. The benefits that they perceived may not necessarily be found in the accounts of men or of people from other cultural backgrounds (or those who practise art-making with less commitment). Nevertheless, descriptions of flow abounded in the participants' accounts, including many features closely related to Csikszentmihalyi's previous theorising.

Generalisation from the accounts of small samples remains open to debate. Some authors argue that qualitative findings have transferability (can be generalised) insofar as the findings can be interpreted theoretically. Others argue that the reader has to make a judgement as to whether qualitative findings have relevance to their own contexts (Marshall and Rossman 1995, Coffey and Atkinson 1996, Seale 1999).

The interpretation of qualitative data is inevitably dependent upon the researchers' own personal and professional sensitivities. It was helpful to bring different professional perspectives, together with flow theory, to enhance the confirmability (or reliability) of the analysis. Nevertheless, there is inevitably a subjectivity about coding complex verbal reflections on personal experience. Neither the template approach nor a fully inferential approach can offer certainty that all meanings have been captured in the ways that the participants intended. Participant validation of themes can provide a helpful additional strategy for enhancing rigour, but in a context where some participants had become very ill or had died since providing their accounts, this strategy was excluded.

\section{Conclusion}

This study has found that some women take up or intensify their involvement in visual art-making after a diagnosis of cancer. Such creative activity affords valued opportunities for experiencing flow and creative adventures. These experiences enhance perceived quality of life; for example, through offering deep immersion in the activity and thereby drawing attention away from symptoms and worry about illness and also through facilitating confidence, control and psychological growth.

\section{Acknowledgements}

The authors are grateful to the participants for sharing their experiences and to the Arts and Humanities Research Council for funding the study. 


\section{References}

Bury M (1982) Chronic illness as biographical disruption. Sociology of Health and IIIness, 4(2), 167-82.

Carpenter J, Brockopp D, Andrykowski M (1999) Self-transformation as a factor in the self-esteem and well-being of breast cancer survivors. Journal of Advanced Nursing, 29(6), 1402-11.

Coffey A, Atkinson P (1996) Making sense of qualitative data: complementary research strategies. London: Sage.

Csikszentmihalyi M (1990) Flow: the psychology of optimal experience. New York: Harper and Row.

Csikszentmihalyi M (1996) Creativity: flow and the psychology of discovery and invention. New York: Harper Collins.

Csikszentmihalyi M (1997) Finding flow: the psychology of engagement with everyday life. New York: Basic Books.

Dickerson A (2000) The power and flow of occupation illustrated through scrapbooking. Occupational Therapy in Health Care, 12(2/3), 127-40.

Emerson $\mathrm{H}$ (1998) Flow and occupation: a review of the literature. Canadian Journal of Occupational Therapy, 65(1), 37-44.

Frank A (1991) At the will of the body: reflections on illness. New York: Houghton Mifflin.

Laubmeier K, Zakowski S (2004) The role of objective versus perceived life threat in the psychological adjustment to cancer. Psychology and Health, 19(4), 425-37.

Marshall C, Rossman G (1995) Designing qualitative research. 2nd ed. London: Sage.

Mathieson C, Stam H (1995) Renegotiating identity: cancer narratives. Sociology of Health and Illness, 17(3), 283-306.

Miles M, Huberman A (1994) Qualitative data analysis: an expanded sourcebook. London: Sage.

Nakamura J, Csikszentmihalyi M (2002) The construction of meaning through vital engagement. In: CLM Keyes, J Haidt, eds. Flourishing: positive psychology and the life well-lived. Washington: American Psychological Association, 83-104.
Rebeiro K, Polgar J (1999) Enabling occupational performance: optimal experiences in therapy. Canadian Journal of Occupational Therapy, 66(1), 14-22.

Reynolds F (2003) Exploring the meanings of artistic occupation for women living with chronic illness: a comparison of template and interpretative phenomenological approaches to analysis. British Journal of Occupational Therapy, 66(12), 551-58.

Saegrov S, Halding A (2003) What is it like living with the diagnosis of cancer? European Journal of Cancer Care, 13(2), 145-53.

Scheerer C, Cahill L, Kirby K, Lane J (2004) Cake decorating as occupation: meaning and motivation. Journal of Occupational Science, 11(2), 68-74.

Seale C (1999) The quality of qualitative research. London: Sage.

Tocher M (2002) How to ride a dragon: women with breast cancer tell their stories. Toronto, ON: Key Porter Books.

Unruh A, Elvin N (2004) In the eye of the dragon: women's experience of breast cancer and the occupation of dragon boat racing. Canadian Journal of Occupational Therapy, 71(3), 138-49.

Unruh A, Smith N, Scammell C (2000) The occupation of gardening in life-threatening illness: a qualitative pilot project. Canadian Journal of Occupational Therapy, 67(1), 70-77.

Urcuyo K, Boyers A, Carver C, Antoni M (2005) Finding benefit in breast cancer: relations with personality, coping and concurrent well-being. Psychology and Health, 20(2), 175-92.

\section{Authors}

Frances Reynolds, PhD, Senior Lecturer in Psychology, Division of Occupational Therapy, School of Health Sciences and Social Care, Brunel University, Borough Road, Isleworth, Middlesex TW7 5DU. Email: frances.reynolds@brunel.ac.uk

Sarah Prior, MSc, Lecturer in Occupational Therapy, Division of Occupational Therapy, School of Health Sciences and Social Care, Brunel University, Borough Road, Isleworth, Middlesex TW7 5DU. Email: sarah.prior@brunel.ac.uk

\section{Focus on Research}

Theses donated to the COT library are available on loan; please contact the library for details.

\section{Peri Hanzouli}

'Getting better': a qualitative study exploring the perceptions of hope for people recovering from mental distress. University of Portsmouth, 2005. MSc Health Research and Development.

Hope is widely recognised as an important factor in helping to facilitate recovery from illness. However, very little research has been carried out to determine whether a connection exists between hope and recovery for people living with severe and enduring mental distress.

This study used a qualitative methodology; incorporating interpretive phenomenological analysis to explore the significance of hope for people receiving interventions from a recovery-oriented occupational therapy service. Three men and two women participated in semi-structured interviews and were asked questions around the themes of pre-recovery, recovery and hope. The analysis uncovered three main themes: connectedness, the power of other people and from thinking to doing.

The study outcomes both challenge and strengthen published perceptions of hope. The findings reinforce the value of hope in the recovery process and indicate the existence of a link between hope, recovery and a hierarchy of needs. They also indicate the important role other people have to play in making recovery a reality and underline the overwhelming drive expressed by all participants to overcome the sense of exclusion bought about by the presence of mental illness and reintegrate back into their communities and move on with their lives. 